\title{
UTILIZAÇÃO DE PENTOXIFILINA E ANTIOXIDANTES NA CRIOPRESERVAÇÃO DO SÊMEN BOVINO: QUALIDADE SEMINAL E ESTRESSE OXIDATIVO
}

\author{
UTILIZATION OF PENTOXIFYLLINE AND ANTIOXIDANTS IN CRYOPRESERVATION OF \\ BOVINE SEMEN: SEMEN QUALITY AND OXIDATIVE STRESS
}

\author{
M. F. DUARTE JUNIOR ${ }^{1}$; L. K. H. ZERVOUDAKIS ${ }^{2}$; J. T. ZERVOUDAKIS ${ }^{2}$; M. M. NICHI ${ }^{3}$; \\ L. E. S. SILVA ${ }^{4}$; P. P. TSUNEDA ${ }^{4}$; F. A. P. B. ARGUELLO ${ }^{5}$; J. D. A. LOSANO ${ }^{3}$
}

\begin{abstract}
RESUMO
O presente estudo avaliou a adição da pentoxifilina, tocoferol, ascorbato e suas combinações sobre a proteção da célula espermática bovina contra os efeitos deletérios da criopreservação. Foram utilizados 24 touros Nelores (Bos taurus indicus), criados em sistema semi-intensivo. Foi coletado um ejaculado de cada reprodutor, diluídos em TRIS-citratogema-glicerol e divididos em seis partes. Cada parte foi suplementada da seguinte maneira: sem aditivos (controle), tocoferol $(10 \mathrm{mmol} / \mathrm{mL})$, tocoferol $(10 \mathrm{mmol} / \mathrm{mL})+$ pentoxifilina $(1 \mathrm{mg} / \mathrm{mL})$, ascorbato $(0,45 \mathrm{mg} / \mathrm{mL})$, ascorbato $(0,45 \mathrm{mg} / \mathrm{mL})+$ pentoxifilina $(1 \mathrm{mg} / \mathrm{mL})$ ou pentoxifilina $(1 \mathrm{mg} / \mathrm{mL})$. Após o descongelamento, as amostras foram avaliadas quanto à motilidade e características do movimento, integridade da membrana plasmática e de acrossomo e atividade mitocondrial. Os níveis de peroxidação lipídica espontânea e induzida foram avaliados pela produção de substâncias reativas ao ácido tiobarbitúrico (TBARS). A suplementação com pentoxifilina, tocoferol, ascorbato e suas combinações, não alterou $(\mathrm{P}>0,05)$ a atividade mitocondrial, integridade acrossomal, e a concentração de TBARS espontâneo e induzido. A adição de tocoferol + pentoxifilina reduziu a motilidade progressiva quando comparado ao ascorbato e também a integridade da membrana espermática quando comparado ao controle e ao ascorbato $(\mathrm{P}<0,05)$. Já a adição de ascorbato + pentoxifilina foi deletéria sobre linearidade em comparação ao tratamento ascorbato $(\mathrm{P}<0,05)$. A adição de ascorbato, tocoferol e pentoxifilina individualmente ou em combinação, não foi eficiente em diminuir os danos causados pela criopreservação e estresse oxidativo em amostras pós descongelamento de sêmen bovino.
\end{abstract}

PALAVRAS-CHAVE: Ascorbato. EROs. Espermatozóide. Estresse oxidative. Tocoferol.

\section{SUMMARY}

The present study evaluated the addition of pentoxifylline, tocopherol and ascorbate and their combinations on the protection of bovine spermatic cells against the deleterious effects of cryopreservation. A total of 24 Nelore bulls (Bos Taurus indicus) were included in this study, raised in a semi-intensive system. One ejaculation was collected from each bull and diluted in tris-citrate-yolk-glycerol, divided into six portions, and then supplemented with: no additives (control); tocopherol $(10 \mathrm{mmol} / \mathrm{ml})$, tocopherol $(10 \mathrm{mmol} / \mathrm{ml})+$ pentxoifylline $(1 \mathrm{mg} / \mathrm{ml})$, ascorbate $(0.45 \mathrm{mg} / \mathrm{ml})$, ascorbate $(0.45 \mathrm{mg} / \mathrm{ml})+$ pentoxifylline $(1 \mathrm{mg} / \mathrm{ml})$ and pentxoifylline $(1 \mathrm{mg} / \mathrm{ml})$. After thawing, the samples were evaluated for motility and characteristics of movement, acrosomal and plasma membrane integrity, and mitochondrial activity. Spontaneous and induced lipid peroxidation levels were evaluated by the production of thiobarbituric acid reactive substances (TBARS). Supplementation with pentoxifylline, tocopherol and ascorbate and their combinations, did not alter mitochondrial activity, acrosomal integrity, or the spontaneous and induced TBARS concentration $(\mathrm{P}>0.05)$. The addition of tocopherol + pentoxifylline reduced progressive sperm motility when compared to ascorbate as well as the spermatic membrane integrity when compared to the control and ascorbate treatments $(\mathrm{P}<0.05)$. When ascorbate + pentoxifylline were added, linearity was decreased compared to the ascorbate treatment $(\mathrm{P}<0.05)$. The ascorbate, tocopherol and pentoxifylline additions, both individually and in combinations, were inefficient in decreasing the damage caused by cryopreservation and oxidative stress in post-thawed bovine semen samples.

KEY-WORDS: Ascorbate. ROSs. Sperm cell. Oxidative stress. Tocopherol.

\footnotetext{
${ }^{1}$ Doutor em Ciência Animal, PPGCA, UFMT. Cuiabá-MT, Brasil. Autor para correspondência: moacirjunior_vet@hotmail.com

${ }^{2}$ Programa de Pós-Graduação em Ciência Animal, Universidade Federal de Mato Grosso, Cuiabá-MT, Brasil.

3 Departamento de Reprodução Animal, FMVZ-USP

4 Doutorando do Programa de Pós-Graduação em Ciência Animal, Universidade Federal de Mato Grosso, Cuiabá-MT, Brasil.

5 Mestre em Ciência Animal, PPGCA, UFMT. Cuiabá-MT, Brasil
} 


\section{INTRODUÇÃO}

O uso de tecnologias da reprodução assistida, que tem o sêmen criopreservado como parte fundamental, é imprescindível em um modelo pecuário que visa otimizar características produtivas e reprodutivas do rebanho (HOLT, 2000).

Entretanto, o processo de criopreservação do sêmen resulta em diminuição de qualidade em cerca de 40-50\% quando comparada ao sêmen fresco, as razões para essas perdas são várias como morte celular ou danos no estado funcional dos espermatozoides sobreviventes levando a uma redução de fertilidade (WATSON, 2000). Esses danos oxidativos ocorrem devido formação excessiva de espécies reativas ao oxigênio (ROS), principalmente o ânion superóxido $\left(\mathrm{O}_{2}^{-}\right)$, o radical hidroxila $\left(\mathrm{OH}^{*}\right)$ e o peróxido de hidrogênio $\left(\mathrm{H}_{2} \mathrm{O}_{2}\right)$ (MAIA e BICUDO, 2009), induzindo a peroxidação lipídica que acarreta alterações na estrutura e na permeabilidade das membranas celulares, alterando sua funcionalidade, causando disfunção espermática e diminuição da motilidade e fertilidade (DROGE, 2002).

Em pequenas quantidades, as ROS são necessárias para o funcionamento normal da célula (ex: a capacitação espermática, hiperativação da motilidade e reação acrossomal) (O'FLAHERTY et al., 2003), o problema é quando ocorre desbalanço no sistema oxidante-antioxidante, em favor do oxidante, provocando efeitos deletérios através do estresse oxidativo (DOWLING e SIMMONS, 2009).

O tocoferol é considerado como o principal antioxidante de membranas celulares, pois não atua somente eliminando as ROS da membrana, mas também intercepta radicais peroxil e álcoois, que são gerados durante a conversão de hidroperóxidos lipídicos e alimentam a reação em cadeia da peroxidação, impedindo que este processo prejudicial se propague através da membrana plasmática (BANSAL e BILASPURI, 2009). O ascorbato é um potente antioxidante hidrossolúvel que melhora a motilidade e viabilidade espermática pós descongelamento (HU et al., 2010). E a pentoxifilina é um derivado da metilxantina, inibidor da fosfodiesterase, aumentando concentrações intracelulares de adenosina monofosfato cíclico (AMPc) que prolonga o tempo de viabilidade e a motilidade pós descongelamento do sêmen criopreservado bovino (DE LA VEGA et al., 1997) e refrigerado de equinos (GOULART et al., 2004).

Com isso, objetivou-se avaliar os efeitos da adição da pentoxifilina, tocoferol e ascorbato separados ou associados na proteção da célula espermática bovina contra os efeitos provocados pela criopreservação.

\section{MATERIAL E MÉTODOS}

Foram utilizados 24 reprodutores da raça Nelore (Bos taurus indicus) com idade média de 31 meses e peso vivo médio de $632 \mathrm{~kg}$, criados em sistema semiintensivo, com boa condição corporal (escore 3 na escala 1-5), provenientes da Fazenda Paraíso Toca do Tatu, município de Santo Antônio do Leverger-MT, mantidos em pasto de Brachiaria brizantha cv. Marandu, com mistura mineral comercial e água ad libtum. Foi coletado um ejaculado de cada reprodutor através do método de eletroestimulação, em seguida alíquotas foram retiradas para a realização dos exames imediatos para avaliação do ejaculado. Ejaculados com valores inferiores a $70 \%$ de motilidade e com a porcentagem de patologia espermáticas totais superiores a $30 \%$ foram descartados (CBRA, 2013). Os ejaculados que estavam dentro dos parâmetros foram encaminhados para o congelamento manual, que foi realizado em laboratório montado em um local próximo à coleta, sem o controle da temperatura ambiental.

Após avaliação imediata, cada ejaculado foi dividido em seis frações e diluído em extensor TRIScitrato-gema (3,187g TRIS-hidroximetil amino metano; $1,78 \mathrm{~g}$ ácido cítrico monohidratado; $1,316 \mathrm{~g}$ frutose; 80 $\mathrm{mL}$ água destilada; $20 \mathrm{~mL}$ gema de ovo; $1000 \mu \mathrm{g} / \mathrm{mL}$ diluidor de estreptomicina; $1000 \mathrm{UI} / \mathrm{mL}$ diluidor de penicilina para cada $100 \mathrm{~mL}$ de diluidor) (Fração A) na concentração de $10^{8}$ espermatozoides/mL. Sendo então, resfriadas por 4 horas a $4^{\circ} \mathrm{C}$. Em seguida, foi adicionada a Fração B (TRIS-citrato-gema $+8 \%$ glicerol) na proporção 1:1.

Os aditivos utilizados foram: $\mathrm{CO}$ - Controle (sem aditivos); TO- tocoferol $(10 \mathrm{mmol} / \mathrm{mL})$; TOPEtocoferol $(10 \mathrm{mmol} / \mathrm{mL})+$ pentoxifilina $(1 \mathrm{mg} / \mathrm{mL})$; ASascorbato $(0,45 \mathrm{mg} / \mathrm{mL})$; ASPE- ascorbato $(0,45 \mathrm{mg} / \mathrm{mL})$ + pentoxifilina $(1 \mathrm{mg} / \mathrm{mL})$; PE- pentoxifilina $(1 \mathrm{mg} / \mathrm{mL})$. Os aditivos foram adicionados ao sêmen diluído no momento do envase em palhetas de 0,5 mL. Em seguida, elas foram colocadas a cinco $\mathrm{cm}$ de vapor de nitrogênio por 15 minutos a $-120^{\circ} \mathrm{C}$, e mergulhadas em nitrogênio líquido $\left(-196^{\circ} \mathrm{C}\right)$, sendo posteriormente armazenadas em botijões criogênicos. $\mathrm{O}$ descongelamento do sêmen foi realizado em banho-maria a $37^{\circ} \mathrm{C}$ por 30 segundos.

Após o descongelamento das amostras, foram retiradas alíquotas para avaliação da motilidade espermática e avaliação do estresse oxidativo. Posteriormente, lâminas foram confeccionadas para avaliação da integridade da membrana plasmática (WHO, 1992), integridade acrossomal (POPE et al., 1991) e atividade citoquímica mitocondrial (HRUDKA, 1987).

Para integridade de membrana plasmática foi utilizada a coloração de eosina-nigrosina, identificando os espermatozoides vivos e mortos. Para a confecção da lâmina retirou-se uma alíquota de sêmen $(8 \mu \mathrm{l})$ e misturou-se ao corante na proporção $1: 1$, o preparo era mantido incubado por cerca de 60 segundos em mesa aquecida a $37^{\circ} \mathrm{C}$ antes de se realizar o esfregaço sobre lâminas de microscopia. A avaliação dos espermatozoides foi feita em magnificação de 1000 vezes, sob óleo de imersão, usando microscopia convencional. Foram avaliados 100 espermatozoides por lâmina, e classificados em células com membrana íntegra/vivo (não coradas) e não íntegra/morto (coradas).

Para integridade acrossomal foi utilizada a Coloração Simples Fast-Green/Rosa-Bengala. Na confecção das lâminas, retirou-se uma alíquota de sêmen $(7 \mu \mathrm{l})$ e misturou-se ao corante na proporção $1: 1$.Este preparo era mantido incubado por cerca de 60 segundos em mesa aquecida a $37^{\circ} \mathrm{C}$ antes de se 
realizar o esfregaço sobre lâminas de microscopia. A avaliação dos espermatozoides foi feita em magnificação de 1000 vezes, sob óleo de imersão, usando microscopia convencional. Foram avaliados 100 espermatozoides por lâmina, e classificados em células com acrossomo íntegro (região acrossomal de coloração lilás a roxa, ligeiramente mais escura que a região pós acrossomal) e acrossomo não-íntegro (região acrossomal de coloração rosa, ligeiramente mais clara que a região pós acrossomal).

Para avaliação de atividade citoquímica mitocondrial, uma alíquota de $25 \mu \mathrm{L}$ de sêmen foi incubada com $25 \mu \mathrm{L}$ de DAB (3,3'-diaminobenzidina) (1mg/mL PBS) a $37^{\circ} \mathrm{C}$ (banho-maria), em condições de luminosidade reduzida, durante uma hora. Após a incubação foram realizadas extensões em lâmina, e fixadas em formaldeído a $10 \%$ por 10 minutos e secos ao ar protegidas de luz. A avaliação foi realizada em microscopia de contraste de fase sob magnificação de 1000x, em imersão. Foram classificados 100 espermatozóides por amostra, e avaliados segundo a atividade mitocondrial da peça intermediária, obedecendo uma escala de quatro classes propostas por Hrudka (1987), onde: classe I (DAB 1; todas as mitocôndrias ativas, células espermáticas com peça intermediária totalmente corada), classe II (DAB 2; células espermáticas com segmentos ativos e inativos com predominância dos ativos, corados, indicando atividade mitocondrial média a alta), classe III (DAB 3 ; espermatozoides com menos da metade da bainha mitocondrial ativa), classe IV (DAB 4; espermatozoides completamente inativos com peça intermediária totalmente descorada).

A motilidade espermática pós-descongelamento foi avaliada no analisador computadorizado Hamilton Thorne (CASA - Computer-Assisted Sperm Analysis; HTR IVOS II). O equipamento foi calibrado de acordo com o padrão para avaliação de célula espermática bovina, com 30 quadros a uma taxa de $60 \mathrm{~Hz}$, contraste mínimo de 80, tamanho mínimo da célula de 5 pixels. As variáveis observadas foram motilidade (MOT;\%), motilidade progressiva (PROG; \%), velocidade média de trajetória (VAP; $\mu \mathrm{m} / \mathrm{s})$, linearidade (LIN; \%) e amplitude de deslocamento (ALH; $\mu \mathrm{m}$ ).

O estresse oxidativo espontâneo (TBARS espontâneo) foi calculado segundo a metodologia de Ohkawa et al. (1979) adaptado. O método se baseia na reação de duas moléculas de ácido tiobarbitúrico (TBA) com uma molécula de MDA, reação esta que ocorre em altas temperaturas e baixo $\mathrm{pH}$, e que resulta na formação de um cromógeno rosa que pode ser quantificado com espectrofotômetro. Após o descongelamento $500 \mu \mathrm{L}$ de sêmen e $1000 \mu \mathrm{L}$ de uma solução a $10 \%$ (v:v) de ácido tricloroacético gelado (TCA 10\%) foram homogeneizados e centrifugados $\left(18.000 \mathrm{~g}, 15 \mathrm{~min}, 15^{\circ} \mathrm{C}\right)$, para a precipitação de proteínas. Após centrifugação uma alíquota do sobrenadante $(500 \mu \mathrm{L})$ foi misturado com $500 \mu \mathrm{L}$ de $1 \%$ (v:v) de ácido tiobarbitúrico (TBA 1\%, diluído em $0,05 \mathrm{~N}$ de $\mathrm{NaOH})$ em tubos e incubado em água fervente $\left(90 \mathrm{a} 100^{\circ} \mathrm{C}\right)$ por $15 \mathrm{~min}$. Após este período, os tubos contendo a mistura foram imediatamente resfriados em banho de gelo $\left(0^{\circ} \mathrm{C}\right)$ para parar a reação.
A absorbância das amostras foram então quantificadas utilizando-se um espectrofotômetro em comprimento de onda de $532 \mathrm{~nm}$. Os resultados foram comparados a uma curva padrão previamente preparada com uma solução padrão de MDA. A concentração de TBARS foi determinada utilizando um valor de $1,56 \times 10^{5}$ $\mathrm{M} / \mathrm{mL}$ com o coeficiente de extinção molar do MDA. $\mathrm{O}$ índice de peroxidação lipídica foi descrito em nanogramas de TBARS por $10^{6}$ espermatozoides (BUEGE; AUST, 1978). Para a determinação do estresse oxidativo induzido (ou lipoperoxidação induzida, TBARS induzido) uma amostra de $200 \mu \mathrm{L}$ de sêmen foi inicialmente lavado duas vezes, com a finalidade de remover os resquícios de diluidor, acrescendo $1600 \mu \mathrm{L}$ de PBS, homogeneizando, centrifugando $(800 \mathrm{~g}, 10 \mathrm{~min})$ e retirando-se $1600 \mu \mathrm{L}$ dopreparo. Após a lavagem foi acrescido sulfato de ferro $(50 \mu \mathrm{L}, 4 \mathrm{mM})$ e ascorbato de sódio $(50 \mu \mathrm{L}, 20$ $\mathrm{mM})$ aos $200 \mu \mathrm{L}$ da suspensão espermática lavada. Em seguida a amostra foi incubada por uma hora e meia a $37^{\circ} \mathrm{C}$ (banho-maria) com a tampa aberta. Após esse período foi quantificado o estresse oxidativo (BUEGE; AUST, 1978). Os reagentes utilizados eram da marca Sigma-Aldrich (Brasil).

O experimento foi raealizado em delineamento inteiramente casualizado. Para as variáveis paramétricas os dados foram analisados através da ANOVA e comparados pelo teste de média Tukey. As variáveis não paramétricas foram comparadas pelo teste Kruskal-Wallis. Ainda foi utilizada análise de correlação de Spearman. Os dados foram analisados com nível de significância de 5\%, sendo considerado como tendência estatística valores de P entre 5 e $10 \%$ (SAS -versão 9.2).

\section{RESULTADOS}

$\mathrm{O}$ uso dos diferentes aditivos avaliados alterou a variável LIN ( $\mathrm{P}=0,0496)$, os valores de AS foram superiores ao de ASPE (44,83 $\pm 2,52$ vs 36,16 $\pm 3,0$, respectivamente) mas não diferiram de $\mathrm{PE}, \mathrm{TOPE}, \mathrm{CO}$ e TO $(42,45 \pm 2,8 ; 42,00 \pm 1,49 ; 39,9 \pm 2,85$ e $39,12 \pm$ 3,3 respectivamente) e uma tendência de alteração para PROG (P = 0,0922) (Tabela 1).

Para o sêmen suplementado com ASPE verificouse uma correlação negativa entre DABII e MOT ( $\mathrm{r}=$ 0,29; $\mathrm{P}=0,0004)$ e PROG ( $\mathrm{r}=-0,24 ; \mathrm{P}=0,0032)$. Já para TO verificou-se uma correlação negativa entre DAB III e MOT ( $\mathrm{r}=-0,46 ; \mathrm{P}=0,0250)$, PROG ( $\mathrm{r}=$ $0,47 ; \mathrm{P}=0,0209)$ e VAP $(\mathrm{r}=-0,50 ; \mathrm{P}=0,0151)$; e entre DAB IV e PROG ( $\mathrm{r}=-0,41 ; \mathrm{P}=0,0495)$ e tendência estatística com VAP $(\mathrm{r}=-0,38 ; \mathrm{P}=0,0722)$.

$\mathrm{O}$ uso de aditivos alterou a integridade de membrana plasmática $(\mathrm{P}=0,0065)$, os valores do $\mathrm{CO}$ e AS foram superiores ao de TOPE $(31,67 \pm 2,81$ e 31,08 $\pm 2,42$ vs $20,17 \pm 3,49$, respectivamente) mas não diferiram de TO, PE e ASPE $(28,25 \pm 3,03 ; 24,83 \pm$ 3,02 e 23,79 \pm 2,84, respectivamente) (Figura 1). Foram observadas ainda, correlações positiva entre integridade de membrana e células DAB I para $\mathrm{PE}(\mathrm{r}=$ $0,72 ; \mathrm{P}<0,0001)$ e ASPE $(\mathrm{r}=0,54 ; \mathrm{P}<0,0001)$ e tendência de correlação para TO $(\mathrm{r}=0,40 ; \mathrm{P}=0,0578)$ e TOPE $(\mathrm{r}=0,35 ; \mathrm{P}=0,0876)$ e negativa entre 
integridade de membrana e células DAB II para $\mathrm{PE}(\mathrm{r}=$ -0,71; $\mathrm{P}<0,0001)$ e ASPE $(\mathrm{r}=-0,41 ; \mathrm{P}<0,0001)$ e tendência para TOPE ( $\mathrm{r}=-0,39 ; \mathrm{P}=0,0549)$; $\mathrm{e}$ integridade de membrana e células DAB IV para TO ( $\mathrm{r}$
$=-0,47 ; \mathrm{P}=0,0217)$, TOPE $(\mathrm{r}=-0,45 ; \mathrm{P}=0,0269), \mathrm{AS}$

$(\mathrm{r}=-0,62 ; \mathrm{P}=0,0013)$ e ASPE $(\mathrm{r}=-0,43 ; \mathrm{P}<0,0001)$.

Tabela 1 - Média \pm desvio padrão e nível de significância $(\mathrm{P})$ das características de movimento (CMOV) pósdescongelamento de amostras de sêmen bovino, para os diferentes aditivos, testados através do CASA

\begin{tabular}{|c|c|c|c|c|c|c|c|}
\hline \multirow[b]{2}{*}{ CMOV } & \multicolumn{6}{|c|}{ Aditivos } & \multirow[b]{2}{*}{$\mathrm{P}$} \\
\hline & $\mathrm{CO}$ & TO & TOPE & AS & ASPE & $\mathrm{PE}$ & \\
\hline МOT\% & $7,25 \pm 1,70$ & $8,66 \pm 2,45$ & $4,41 \pm 0,97$ & $9,37 \pm 2,00$ & $5,58 \pm 1,68$ & $7,45 \pm 1,60$ & 0,6811 \\
\hline PROG\% & $3,0 \pm 0,72^{\mathrm{ab}}$ & $3,87 \pm 1,36^{\mathrm{ab}}$ & $1,50 \pm 0,42^{\mathrm{b}}$ & $4,58 \pm 1,06^{\mathrm{a}}$ & $2,16 \pm 0,68^{\mathrm{ab}}$ & $2,75 \pm 0,70^{\mathrm{ab}}$ & 0,0922 \\
\hline $\mathrm{VAP} \mu \mathrm{m} / \mathrm{s}$ & $64,38 \pm 5,39$ & $57,79 \pm 5,16$ & $61,59 \pm 2,56$ & $64,80 \pm 4,52$ & $56,26 \pm 5,12$ & $58,63 \pm 3,58$ & 0,8057 \\
\hline LIN\% & $39,9 \pm 2,85^{\mathrm{ab}}$ & $39,12 \pm 3,3^{\mathrm{ab}}$ & $42,00 \pm 1,49^{\mathrm{ab}}$ & $44,83 \pm 2,52^{\mathrm{a}}$ & $36,16 \pm 3,0^{b}$ & $42,45 \pm 2,8^{\mathrm{ab}}$ & 0,0496 \\
\hline ALH $\mu \mathrm{m}$ & $5,02 \pm 0,65$ & $5,37 \pm 0,62$ & $6,07 \pm 0,57$ & $5,58 \pm 0,46$ & $5,92 \pm 0,67$ & $5,72 \pm 0,60$ & 0,5690 \\
\hline
\end{tabular}

$\overline{\mathrm{a}, \mathrm{b}}$ Letras diferentes na mesma linha indicam que houve diferença $(\mathrm{P}<0,05)$ pelo teste Tukey. MOT: motilidade, PROG: motilidade progressiva, VAP: velocidade média de trajetória, LIN: linearidade e ALH: amplitude de deslocamento. CO- Controle (sem aditivos); TO- tocoferol $(10 \mathrm{mmol} / \mathrm{mL})$; TOPE- tocoferol $(10 \mathrm{mmol} / \mathrm{mL})+$ pentoxifilina $(1 \mathrm{mg} / \mathrm{mL})$; AS- ascorbato $(0,45 \mathrm{mg} / \mathrm{mL}) ;$ ASPEascorbato $(0,45 \mathrm{mg} / \mathrm{mL})+$ pentoxifilina $(1 \mathrm{mg} / \mathrm{mL}) ;$ PE- pentoxifilina $(1 \mathrm{mg} / \mathrm{mL})$

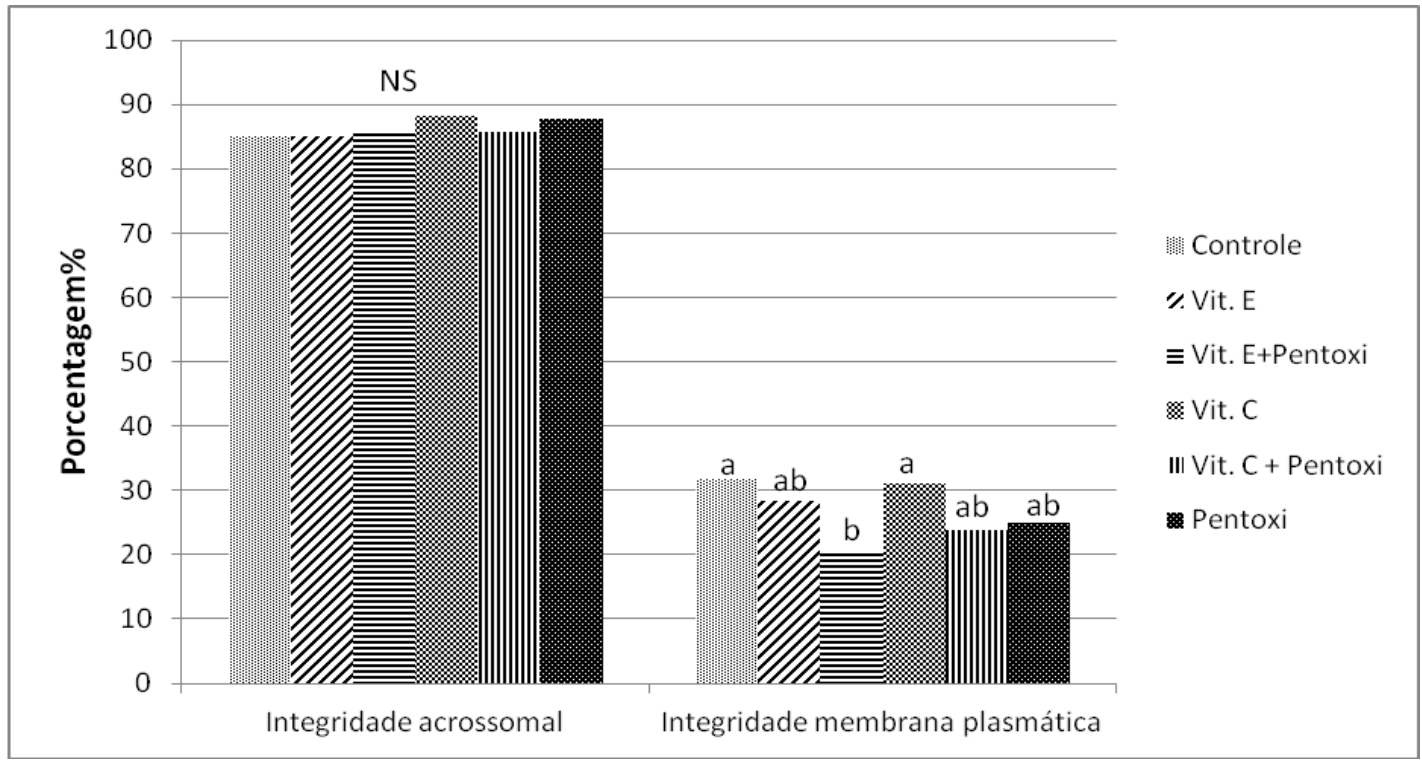

Figura 1 - Valores médios obtidos dos parâmetros de integridade do acrossoma e da membrana plasmática espermática de amostras de sêmen bovino pós-descongelamento, para os diferentes grupos. Em cada conjunto de barras, médias com letras diferentes, diferem significativamente entre si $(\mathrm{P}<0,05)$ pelo teste Tukey.

Observou-se uma correlação negativa entre TBARS induzido e células DAB II para ASPE ( $\mathrm{r}=$ $0,31 ; \mathrm{P}=0,0001)$ e tendência de correlação para PE ( $\mathrm{r}$ $=-0,38 ; \mathrm{P}=0,0650)$, TOPE $(\mathrm{r}=-0,36 ; \mathrm{P}=0,0832) \mathrm{e}$ AS $(r=-0,38 ; P=0,0666)$. E ainda uma correlação positiva para TBARS espontâneo e células PROG para AS $(r=0,54 ; P=0,0276)$.

A atividade mitocondrial (Tabela 2) e concentrações de TBARS espontâneo e induzido (Tabela 3) não foram influenciadas pela suplementação $(\mathrm{P}>0,05)$.

\section{DISCUSSÃO}

Não há nenhuma informação na literatura sobre a adição de pentoxifilina associado à tocoferol ou ascorbato na criopreservação de sêmen bovino. No entanto, nossos resultados demonstraram que a combinação desses aditivos provocou um efeito antagônico, sendo que os grupos ASPE e TOPE apresentaram as menores média para integridade de membrana (Figura 1), MOT e PROG (Tabela 1) entre os tratamentos. Gradil e Ball (2000) utilizando concentração de 1 e $2 \mathrm{mg} / \mathrm{mL}$ de pentoxifilina no extensor de sêmen equino criopreservado, observaram redução significativa $(\mathrm{P}<0,001)$ em todos os parâmetros de movimento espermático pósdescongelamento avaliados pelo CASA, e sugeriram que a pentoxifilina induziu um gasto energético précongelamento precoce. 
Tabela 2 - Média \pm desvio padrão e nível de significância $(\mathrm{P})$ da atividade citoquímica mitocondrial pósdescongelamento de amostras de sêmen bovino, para os diferentes aditivos

\begin{tabular}{llllllll}
\hline & \multicolumn{7}{c}{ Aditivos } \\
\cline { 2 - 6 } Classes & \multicolumn{1}{c}{ CO } & \multicolumn{1}{c}{ TO } & TOPE & AS & ASPE & PE & P \\
\hline DAB 1 & $46,79 \pm 4,24$ & $49,17 \pm 3,99$ & $43,00 \pm 3,79$ & $47,56 \pm 3,64$ & $39,60 \pm 4,22$ & $42,83 \pm 4,40$ & 0,5707 \\
DAB 2 & $29,12 \pm 2,40$ & $29,60 \pm 2,39$ & $34,54 \pm 1,82$ & $29,26 \pm 2,17$ & $34,43 \pm 2,64$ & $31,79 \pm 2,22$ & 0,1728 \\
DAB 3 & $14,87 \pm 2,14$ & $12,69 \pm 2,32$ & $15,00 \pm 2,28$ & $13,21 \pm 2,12$ & $16,82 \pm 2,08$ & $16,08 \pm 2,23$ & 0,6281 \\
DAB 4 & $9,25 \pm 1,79$ & $8,30 \pm 1,45$ & $7,58 \pm 1,23$ & $10,00 \pm 1,67$ & $9,13 \pm 1,70$ & $9,33 \pm 1,59$ & 0,9562 \\
\hline
\end{tabular}

Classes de espermatozoides: (DAB 1) todas mitocôndrias ativas; (DAB 2) predominância de mitocôndrias ativas; (DAB 3) menos da metade das mitocôndrias ativas; (DAB 4) todas mitocôndrias inativas. CO- Controle (sem aditivos); TO- tocoferol (10mmol/mL); TOPE- tocoferol (10mmol/mL) + pentoxifilina $(1 \mathrm{mg} / \mathrm{mL})$; AS- ascorbato $(0,45 \mathrm{mg} / \mathrm{mL})$; ASPE- ascorbato $(0,45 \mathrm{mg} / \mathrm{mL})+$ pentoxifilina $(1 \mathrm{mg} / \mathrm{mL})$; PE- pentoxifilina $(1 \mathrm{mg} / \mathrm{mL})$.

Tabela 3 - Média \pm desvio padrão e nível de significância (P) obtidos da concentração de TBARS (ng/10 ${ }^{6}$ sptz) espontâneo (TE) e induzido (TI) pós-descongelamento, de amostras de sêmen bovino, para os diferentes aditivos, avaliados através de espectrofotômetro

\begin{tabular}{|c|c|c|c|c|c|c|c|}
\hline \multirow[b]{2}{*}{ Parâmetros } & \multicolumn{6}{|c|}{ Aditivos } & \multirow[b]{2}{*}{$\mathrm{P}$} \\
\hline & $\mathrm{CO}$ & TO & TOPE & AS & ASPE & $\mathrm{PE}$ & \\
\hline TE & $5,98 \pm 2,13$ & $6,46 \pm 2,29$ & $6,65 \pm 2,35$ & $6,62 \pm 2,33$ & $5,88 \pm 2,26$ & $7,54 \pm 2,80$ & 0,9882 \\
\hline TI & $62,34 \pm 8,22$ & $66,74 \pm 8,38$ & $63,47 \pm 9,57$ & $58,52 \pm 8,27$ & $63,64 \pm 7,20$ & $61,30 \pm 7,31$ & 0,7668 \\
\hline
\end{tabular}

CO- Controle (sem aditivos); TO- tocoferol $(10 \mathrm{mmol} / \mathrm{mL}) ;$ TOPE- tocoferol $(10 \mathrm{mmol} / \mathrm{mL})+$ pentoxifilina $(1 \mathrm{mg} / \mathrm{mL}) ;$ AS- ascorbato $(0,45 \mathrm{mg} / \mathrm{mL}) ;$ ASPE- ascorbato $(0,45 \mathrm{mg} / \mathrm{mL})+$ pentoxifilina $(1 \mathrm{mg} / \mathrm{mL})$; PE- pentoxifilina $(1 \mathrm{mg} / \mathrm{mL})$.

Dessa forma a associação destes antioxidantes no pré-congelamento, pode ter proporcionado condições favoráveis, que levou a uma maior concentração intracelular de AMPc, liberando energia para atividade celular, aumentando seu metabolismo justamente no momento da adição da fração B do diluidor contendo o glicerol. Dessa forma após o descongelamento as amostras apresentaram menor qualidade, devido ao consumo dos estoques de substrato para produção de ATP, indispensável no movimento espermático levando a redução do metabolismo celular e refletindo negativamente nas características de movimento do espermatozoide. Sendo que, mais estudos são necessários, utilizando adição destes compostos em diferentes momentos da criopreservação, e após o descongelamento das amostras, visando à melhora dos parâmetros seminais avaliados.

$\mathrm{O}$ ascorbato presente na dieta de ruminantes é quase totalmente destruído por microrganismos no rúmen, sendo essencial sua síntese endógena pelo fígado a partir de D-glucose e D-galactose, ou a suplementação exógena, para atender as necessidades fisiológicas em algumas situações como doença e estresse (RANJAN, et al., 2012). Nichi et al., (2006) observaram aumento no número total de defeitos espermáticos e concentração de TBARS no sêmen bovino durante o verão em regiões tropicais (NICHI et al. 2006). Provavelmente em condições de estresse calórico, ocorra déficit de ascorbato, levando a um efeito positivo de sua adição ao meio de criopreservação.

$\mathrm{Hu}$ et al. (2010) trabalharam com adição de diferentes concentrações de ascorbato ao meio diluidor e encontraram efeito benéfico $(\mathrm{P}<0,05)$ para MOT, LIN e ALH quando utilizou a concentração de
$4,5 \mathrm{mg} / \mathrm{mL}$ em relação ao grupo controle. No presente estudo utilizou-se uma concentração dez vezes menor $(0,45 \mathrm{mg} / \mathrm{mL})$, o que possivelmente não proporcionou resultados semelhantes aos de $\mathrm{Hu}$ et al. (2010).

Foi encontrada correlação negativa entre TBARS induzido e células DAB II, na metodologia para determinação do estresse induzido (TBARS induzido) as células são expostas a condições que favorecem a formação de ROS, justamente para testar sua susceptibilidade ao estresse oxidativo. Ainda foi encontrada correlação positiva entre TBARS espontâneo e células PROG para AS, podendo ser uma maior atividade mitocondrial a causa de níveis mais altos de peroxidação lipídica nas amostras. Isto pode ser explicado devido ao fato de que as mitocôndrias são responsáveis pela maior parte da produção endógena de espécies reativas de oxigênio (COPELAND, 2002). No entanto, a produção de espécies reativas de oxigênio é um processo fisiológico importante na hiperativação, reação acrossômica e fusão espermatozoide/oócito (AITKEN et al., 1991) e por isso não podem ser totalmente suprimidas. Sendo assim, mais estudos são necessários para elucidar essa questão.

Para integridade de membrana foi encontrada correlação positiva entre células DAB I (PE, TO, TOPE e ASPE) e negativa com células DAB II (PE, TOPE e ASPE) e DAB IV (TO, TOPE, AS e ASPE), que pode ser explicado, uma vez que a membrana plasmática é a estrutura espermática mais sensível a modificações em situações de injúrias como congelamento (BORGES et al., 2011), e esta recobre a peça intermediária, local onde estão localizadas as mitocôndrias na célula espermática. 
As correlações negativas entre células com menor atividade mitocondrial (DAB II, DAB III e DAB IV) e parâmetros de movimento espermático (MOT, PROG, VAP e LIN) em alguns tratamentos, podem ser explicados pelo fato de que a mitocôndria é responsável por cerca de $90 \%$ da produção de energia celular (COPELAND, 2002), utilizada como substrato para o movimento flagelar (KAMP et al., 2003).

\section{CONCLUSÃO}

A adição de ascorbato, tocoferol e pentoxifilina individualmente ou em combinação, não foram eficientes em diminuir os danos causados pela criopreservação e estresse oxidativo em amostras pósdescongelamento de sêmen bovino.

\section{REFERENCIAS}

AITKEN, R. J.; IRVINE, D. S.; WU, F. C. Prospective analysis of sperm-oocyte fusion and reactive oxygen species generation as criteria for the diagnosis of infertility. American Journal of Obstetrics and Gynecology. v. 164, n. 2, p. 542-551, 1991.

ANDRADE, E.R.; MELO-STERZA, F.A.; SENEDA, M.M.; ALFIERI, A.A.; Consequências da produção das espécies reativas de oxigênio na reprodução e principais mecanismos antioxidantes Revista Brasileira de Reprodução Animal, Belo Horizonte, v.34, n.2, p.79-85, 2010.

BANSAL, A.K.; BILASPURI, G.S. Antioxidant effect of vitamin $\mathrm{E}$ on motility, viability and lipid peroxidation of cattle spermatozoa under oxidative stress. Animal Science and Papers Reports. v.27, n.1, p.5-14, 2009.

BORGES, J.C.; SILVA, M.R.; GUIMARÃES, J.D.; ESPER, C.R.; FRANCESCHINI, P.H. Membrana plasmática de espermatozoides bovinos: efeito de metabólitos do oxigênio, antioxidantes e criopreservação. Revista Brasileira de Reprodução Animal. v.35, n.3, p.303-314, 2011.

BUEGE, J. A.; AUST, S. D. Microsomal lipid peroxidation, Methods of Enzymology, v. 52, n. 1, p. 302-310, 1978.

CBRA. Colégio Brasileiro de Reprodução Animal-. Manual para exame andrológico e avaliação de sêmen animal. 3. ed. Belo Horizonte, 2013, 104 p.

COPELAND W.C. Mitochondrial DNA: methods and protocols. Totowa, NJ: Humana Press, 2002. 420p. Methods in Molecular Biology, v.197.

De la VEGA, A.C.; WILDE, O.R.; CRUZ, M.L. Efectos de la pentoxifilina y la cafeína sobre la motilidade de espermatozoides bovinos criopreservado. Avances em Ciencias Veterinárias. V.12, n.2, p.7579,1997
DOWLING, D.K.; SIMMONS, L.W. Reactive oxygen species as universal constraints in life-history evolution. Proceedings of the Royal Society B. v.276, p.1737-1745, 2009.

DROGE, W. Free Radicals in the Physiological Control of Cell Function. Physiological Reviews v.82 p.47-95, 2002.

GOUlART, H.M.; SILVA, A. E. D.; McMANUS, C. PAPA, F. O. Efeitos da pentoxifilina sobre a viabilidade in vitro dos espermatozoides de equinos, após o resfriamento. Revista Brasileira de Zootecnia. v.33, n.1, p.112-122, 2004.

GRADIL, C.M.; BALL, B.A. The use of pentoxifylline to improve motility of cryopreserved equine spermatozoa. Theriogenology. V.54, p.1041-1047, 2000 .

HOLT, W.V. Basic aspects of frozen storage of semen. Animal Reproduction Science. v.62, p.3-22, 2000.

HRUDKA, F. Cytochemical and ultracytochemical demonstration of cytochrome-c oxidase in spermatozoa and dynamics of changes accompanying ageing or induced by stress. International Journal of Andrology, v. 10, n. 6, p. 809-828, 1987.

HU, J.H.; TIAN, W.Q.; ZHAO, X.L.; ZAN, L.S.; WANG, W.; LI, Q.W.; XIN, Y.P. The cryoprotective effects of ascorbic acid supplementation on bovine sêmen quality. Animal Reproduction Science. v.121, p.72-77, 2010.

KAMP, G.; BUSSELMANN, G.; JONES, N.; WIESNER, B.; LAUTERWEIN, J. Energy metabolism and intracellular $\mathrm{pH}$ in boar spermatozoa. Reproduction, v.126, p.517-525, 2003.

MAIA, M.S.; BICUDO, S.D.; Radicais livres, antioxidantes e função espermática em mamíferos: uma revisão. Revista Brasileira Reprodução Animal. Belo Horizonte, v.33, n.4, p.183-193, 2009.

NICHI, M.; BOLS, P.E.J.; ZUGE, R.M.; BARNABE, V.H.; GOOVAERTS, I.G.F.; BARNABE, R.C.; CORTADA, C.N.M. Seasonal variation in semen quality in Bos indicus and Bos Taurus bulls raised under tropical conditions. Theriogenology. v.66, p.822-828, 2006.

OHKAWA, H.; OHISHI, N.; YAGI, K. Assay for lipid peroxides in animal tissues by thiobarbituric acid reaction. Analytical Biochemistry, v. 95, n. 3, p. 351358, 1979.

O'FLAHERTY, C.; BEORLEGUI, N.; BECONI, M.T. Participation of superoxide anion in the capacitation of cryopreserved bovine sperm. International Journal of Andrology. V.26, p.109-114, 2003. 
POPE, C. E.; ZHANG, Y. Z.; DRESSER, B. L. A simple staining method for evaluating acrossomal status of cat spermatozoa. Journal of Zoo and Wildlife Medicine, v. 22, n. 1, p. 87-95, 1991.

RANJAN, R.; RANJAN, A.; DHALIWAL，G. S.; PATRA, R. C. L-Ascorbic acid (vitamin C) supplementation to optimize health and reproduction in cattle. Veterinary Quarterly. v.1, p. 1-6, 2012.
WATSON, P.F. The causes of reduced fertility with cryopreserved semen. Animal Reproduction Science. v.60-61, p.481-492, 2000.

WHO World Health Organization. WHO laboratory manual for the examination of human semen and semen - cervical mucus interaction. Cambridge: The Press Syndicate of the University of Cambridge, 1992. p.120. 